\title{
DESVIO DE PODER NO DIREITO COMPARADO
}

\section{MARCIA FRATARI MAJADAS*}

Resumo - 1. Introdução - 2. O conceito de desvio de poder no direito comparado - 3. A teoria do desvio de poder no Direito comparado - 4. Modalidade de desvio de poder no Dirieto comparado - 5. A prova do desvio de poder no direito comparado - 6. Conclusão - 7 . Referências bibliográficas

\section{Resumo}

O presente estudo objetiva evidenciar semelhanças e diferenças entre doutrina e jurisprudência no ordenamento jurídico brasileiro, francês, italiano. português, norte-americano, argentino, uruguaio e espanhol. A análise tem como base teórica a jurisprudência do Conselho de Estado Francês, no caso Lesbats, e o acórdão proferido no Tribunal de Justiça do Rio Grande do Norte, na apelação civil $n^{\circ} 1.422$, que focalizou o tema em termos precisos perante o direito brasileiro, baseado em erudito voto do Desembargador Seabra Fagundes. No cotejo, utilizando-se da perspectiva metodológica analítico-comparativa, pôde-se analisar as semelhanças que emergem conhecimentos gerais, que aprimoram o Direito interno. O trabalho assinalou a importância da jurisprudência no desenvolvimento do direito administrativo brasileiro, não só na perspectiva do direito interno, mas também na integração com os direitos europeu, norte-americano e sul americano. Concluiu-se que a Teoria do Desvio de Poder apresenta semelhanças no Direito brasileiro, português, argentino e uruguaio, pois, tanto a jurisprudência quanto a doutrina adotam a nulidade em caso de desvio de poder, mesmo quando a autoridade, embora deixando de executar o fim legal, procure atingir outro objetivo de interesse público; diferentemente do Direito Italiano, Francês e Espanhol, para os quais ofim legal do ato administrativo constitui vinculação da competência. O Direito norte-americano adota o mesmo

* Mestrado em Direito. Área de Concentraçāo: Sistemas de Resolução de Conflitos. UEMG. Campus Fundacional de Ituiutaba.

R. Dir. Adm.,

Rio de Janeiro, 236: 111-120,

Abr./Jun. 2004 
conceito que a jurisprudência francesa e italiana de que a vinculação do ato administrativo, com respeito ao fim de origem legal, obriga a tipicidade do escopo, que é irremovivel e inalterável.

\section{Introduçcio}

O Desvio de Poder em atos administrativos, concernente ao Direito Adminstrativo Comparado, constitui um dos problemas centrais nas formas de atuação do Poder Público frente à sociedade. Justifica-se essa afirmação em virtude de a administração encontrar no processo de realização campo de livre desenvolvimento, no qual the é facultada a seleção da maneira de agir.

No plano jurídico, a Administração funciona sob o controle da legalidade, tendo como tarefa principal a defesa do interesse público. Nessa medida, o principal desafio refere-se ao equacionamento da potestade estatal diante de direitos individuais e coletivos dos cidadãos.

Se, por um lado a Administração Pública se reveste de poder decorrente da soberania estatal, que lhe confere certa autoridade na interação com os administrados, e de certa liberdade de ação, por outro, o Estado, detentor dessa administração, também é sujeito de direitos e obrigações. Esse fato o torna responsável judicialmente por atos que extrapolem essa área de autoridade que o Direito possa vir a lhe conferir.

No Estado de Direito, a função administrativa subordina-se à lei e tem em mira o cumprimento das finalidades contidas na ordenação normativa. O liame que vincula a Administração à lei é mais estrito que o travado entre a lei e o comportamento dos particulares. Vale dizer que, enquanto na atividade privada pode-se fazer tudo o que não é proibido, na atividade administrativa só se faz o que é permitido.

Por isso, FLEINER (1993:37) analisou o preceito da seguinte forma: "Administração legal, então, é aquela posta em movimento pela lei e exercida dentro dos limites de suas disposições". Nesse mesmo entendimento, SEABRA FAGUNDES (1975:17) preleciona: "Administrar é aplicar a lei de ofício". No mesmo compasso, deixou averbado CIRNE LIMA (1954:22). "Jaz conseqüentemente, a Administração Pública debaixo da legislação que deve enunciar a regra do Direito.

Assim, o Direito Brasileiro, na diç̧ão do artigo $5^{\circ}$, II, da Constituição Republicana de 1988, ressoa que "ninguém será obrigado a fazer ou deixar de fazer

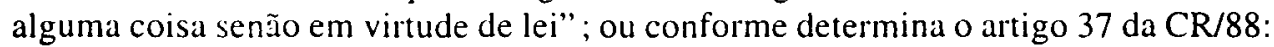
"a Administração direta e indireta dos três poderes, e em todas as órbitas, se assujeitará ao princípio da legalidade"; ou como assertoa o artigo 84 da CR/88 que compete ao Presidente expedir decretos e regulamentos para a fiel execução das leis. De outra parte, o artigo $1^{\circ}$, parágrafo único, da CR/88 avulta que "todo poder emana do povo que o exerce por meio de representantes eleitos ou diretamente (...)".

Vale dizer ainda, pela lógica, que o Estado de Direito sagra a tese da soberania popular, do primado da lei - regra geral, abstrata, impessoal.

Fortalecer o Poder Executivo não significa, porém, convertê-lo em poder arbitrário e incontrastável, mas torná-lo instrumento exato de dosagem entre o poder discricionário e o controle de sua legalidade. O princípio da legalidade sobrevive ao 
crescimento do aparelhamento administrativo e garante à administração o uso do poder discricionário. Elimina qualquer medida jurisdicional de controle da oportunidade, mas, por outro lado, protege o indivíduo contra riscos de desvio de poder.

O vício, que incide sobre o fim do ato administrativo, é o desvio de poder, escopo diverso da lei daquele em que a autoridade administrativa praticou o ato, viciado de sua finalidade, o que gera sua nulidade.

Os atos administrativos constituem-se de elementos essenciais à sua existência jurídica. Aos requisitos necessários à validade dos atos jurídicos em geral - capacidade do agente, objeto lícito, forma prescrita ou não e defesa em lei - associam-se dois outros elementos que firmam balisas de legalidade: os motivos e o fim.

Os motivos são antecedentes de fato ou de direito em que se baseou o agente. O fim é o objetivo de interesse público, definido explícita ou implicitamente na regra do direito, ao qual se deve submeter a manifestação da vontade. Daí, o liame de dependência lógica entre o motivo, conteúdo e fim do ato, cuja relação de pertinência condiciona o exercício da competência conferida pela lei ao agente administrativo.

Assim, quando, no exercício de competência legítima, a autoridade pratica ato formalmente lícito, mas destinando-se a atender a um fim de interesse privado exclusivo ou de outro interesse, estranho à previsão legal, consuma-se sua nulidade pela inobservância da finalidade obrigatória, característica do desvio de poder.

\section{O conceito de desvio de poder no direito comparado}

No Direito comparado Brasileiro, segundo BANDEIRA DE MELLO (1969:426-9), "o desvio de poder não é senão uma modalidade de "abuso de direito", uma expressão deste vício na esfera pública".

Com efeito, a construção da teoria do fenômeno jurídico, a que se denominou desvio de poder, surgiu, precisamente, com o objetivo de impor limitação ao âmbito de atuação discricionária por parte da Administração Pública, com vistas à exclusão de qualquer incidência no campo da arbitrariedade.

O desvio de poder, como vício objetivo, atropela a legalidade do ato, porquanto expressa desconformidade entre $o$ ato em sua finalidade e a norma legal, que contém a previsão abstrata do objeto a ser concretizado.

No Direito Francês, diferentemente do Direito Brasileiro, afirma RIVERO (1975:250) que o desvio de poder é vício que afeta o ato, mediante o qual a Administração prossegue rumo diverso do que the foi assinalado pela norma jurídica; desvia-se, assim, o poder de seu fim legal.

O Direito Italiano diverge, como acontece no Direito Francês, do Direito Brasileiro, uma vez que o legislador Italiano não definiu o conceito de excesso de poder como causa anulatória do procedimento administrativo. Criou a jurisprudência italiana uma coleção de fórmulas em que procura identificar o desajuste entre dados materiais e manifestação subjetiva do agente.

A inexistência ou falsa apreciação dos fatos (travisamento dei fatti), a insuficiência ou a notória impropriedade dos motivos (insuficienza della 
motivazione, illogieità manifesta), a contradição de critérios (contradittorietà di provedimenti, dispontà di trattamento) são modalidades geralmente de excesso de poder administrativo. In TÁCITO (1975:99).

Já o Direito Italiano confunde, numa perfeita identidade de substância, o "eccesso di potere" eo "détournement de pouvoir" do Direito Francês. A jurisprudência italiana acompanha a lição do Conselho de Estado da França e repele tanto o ato administrativo inspirado em um fim de natureza privada, como o que objetive um fim público diverso do endereço legal; são, por igual maneira viciados de sviamento di potere, segundo ZANOBINI (1947:142).

No Direito Português, a doutrina e a jurisprudência adotam a nulidade pelo desvio de poder, mesmo quando a autoridade deixa de executar o fim legal e procura alcançar outro objetivo de interesse público. Segundo CAETANO (1973:506), diferentemente do Direito Italiano e Francês, para os quais o fim legal do ato administrativo constitui vinculação da competência, a autoridade administrativa deve orientar-se na execução material da lei pelo propósito final das facultas agendi, que the foi conferida.

Porém, inocorre nulidade do ato administrativo se o agente associar ao fim legítimo da competência qualquer outro escopo público ou privado, conforme lição de ZANOBINI (1947:142).

O Direito Norte-americano adota o conceito, já assinalado a propósito das jurisprudências francesa e italiana, de que a vinculação do ato administrativo, a respeito do fim de origem legal, obriga à tipicidade do escopo, que é irremovível e inalterável, como assinalou PINTO (1951:153): "o conceito judicial das decisões "dessarrazoadas" ou "arbitrárias" corresponde a "l'application d'une notion très proche du dètournement de pouvoir".

No Direito Argentino, BIELSA (1947:182-226) condiciona a "validade dos atos administrativos ao respeito à finalidade legal”. FIORINI (1948:113) particulariza:

(...) a noção de fim objetivo como um limite à competência discricionária, tal qual no Direito Brasileiro, como assevera TÁCITO (1975:49)(...) "Haverá desvio de poder, ou seja, a aplicação da competência para um fim estranho àquele estabelecido em lei.

No Direito Uruguaio, LASO (1974:449-57) considera "a afirmação do fim como elemento essencial do ato administrativo, como dispõe no Direito Brasileiro, Português e Argentino".

Já no Direito Espanhol, conforme RODÓ (1953:580), "o Tribunal Supremo adota, embora sem menção expressa a doutrina francesa do desvio de poder em acórdão de 21 de junho de 1944, anulatório de decisão municipal por incompatibilidade entre o meio utilizado e o fim".

Assim. o desvio de poder causa a nulidade do ato administrativo, pois fere sua finalidade. 


\section{A teoria do desvio de poder no direito comparado}

A teoria do Desvio de Poder no Direito Brasileiro, como causa de nulidade de atos administrativos, foi elaborada por SEABRA FAGUNDES e mais modernamente por VITOR NUNES LEAL. No passado, o artigo $13, \S 9^{\circ}$, alíneas " $a$ " e " $b$ " da Lei $n^{\circ} 221$, de 20.11.1894, assim determinou:

a - consideram-se ilegais os atos ou decisões administrativas em razões da não aplicação ou indevida aplicação do direito vigente. A autoridade judiciária fundar-se-á em razões jurídicas, abstendo-se de apreciar o merecimento de atos administrativos, sob o ponto de vista de sua conveniência ou oportunidade;

$\mathrm{b}$ - a medida administrativa tomada em virtude de uma faculdade ou poder discricionário somente será havida por ilegal em razão da incompetência da autoridade respectiva ou do excesso de poder.

A mais expressiva decisão judiciária brotou do acórdão, de 28 de julho de 1948 , do Tribunal de Justiça do Rio Grande do Norte, na apelação civil $n^{\circ} 1.422$, com fundamento no voto do Desembargador SEABRA FAGUNDES (1948:52-82). Cogitava-se do exercício do poder de polícia relativo a trânsito, regulado por autoridade estadual competente, que fixaria horário para tráfego de determinada companhia de ônibus, visando prejudicá-la em benefício da empresa concorrente. Decidiu, unanimemente, o Tribunal que o ato da Inspetoria Estadual de Trânsito não atendia ao interesse público previsto na lei, ou seja o bom funcionamento do serviço de transporte, uma vez que objetivava outro fim, estranho ao conteúdo de sua competência. Singulariza-se o voto do jurista Seabra Fagundes pelo reconhecimento da nulidade do ato, impugnado em função do desvio de poder de polícia. Depois de marcar o cunho vinculatório da finalidade, Seabra Fagundes demonstrou a inexistência material dos motivos alegados no ato de autoridade e evidenciou o sentido oculto e ilícito do procedimento administrativo.

Portanto, o Direito Brasileiro é semelhante ao Direito Francês no caso Lesbats, em que, em fevereiro de 1864, no arrêt Lesbats, o Conselho de Estado da França admitiu, pela primeira vez, o " desvio de poder" como uma das hipóteses em que se cabia atacar o ato administrativo no quadro dos recursos, por "excesso de poder"; designação genérica que abrange os vícios de incompetência, de forma, de violação da lei e de desvio de poder. Segundo LAUBADĖRE (1970:502), "Há desvio de poder quando uma autoridade administrativa cumpre um ato de sua competência mas em vista de fim diverso daquele para o qual o ato poderia legalmente ser cumprido".

A aplicação do desvio de poder na França cabe ao Juiz administrativo, verdadeiro criador desse direito pretoriano a que se refere WALLINE (1950:11). Não há, em toda a legislação francesa, qualquer referência expressa ao détournement de pouvoir, como forma de nulidade do ato administrativo. Entretanto, sob tal fundamento, se sucedem no Conselho de Estado recursos contenciosos, moldados na 
jurisprudência, constituindo-se a teoria do desvio de poder em um dos limites mais eficazes aos abusos do Poder Executivo.

Nos Direitos Italiano e Francês, a "teoria do desvio de poder" é de cunho jurisprudencial. O desvio de poder pode ser declarado administrativamente, solvendo-se à revelia da intervenção jurisdicional. Diferentemente, no Direito Brasileiro, leva-se ao exame do motivo do ato administrativo pelo Poder Judiciário, que encontra apoio na jurisprudência e na doutrina.

Não há ofensa à liberdade quando o agente dispõe da discrição. O Poder Judiciário examina o ato administrativo do agente que desviou do fim legal. É da alçada do Poder Judiciário tal averiguação para que cumpra sua função de aplicar a lei.

O Direito Português difere dos Direitos Francês, Brasileiro e Italiano relativamente ao exame de matéria disciplinar, firmado pelo Supremo Tribunal Administrativo, quanto à tipicidade do fim do ato administrativo. Ademais, a anulação contenciosa de atos administrativos não se estende aos atos de governo, aos atos praticados segundo o direito privado e aos atos internos da Administração. Porém, aplica-se a todos os demais casos a competência do órgão jurisdicional especializado, o Supremo Tribunal Administrativo, sem prejuízo da possibilidade de anulação ex officio do ato pela própria administração, conforme CAETANO (1973:477-78).

No Direito Argentino e no Direito Brasileiro, o sistema judicialista inspirou-se na elaboração legislativa e na causa da nulidade do ato. Assim, tem decidido a jurisprudência.

No Direito Uruguaio, conforme documenta LASO (1974:449-57), a jurisprudência dos tribunais tem acolhido largamente a "teoria do desvio de poder".

O Direito Espanhol difere dos Direitos Argentino, Uruguaio, Português e Brasileiro, mas é similar aos Direitos Francês e Italiano, nos quais a nulidade do ato administrativo não ocorre se o agente associar qualquer escopo público ou privado ao fim legítimo da competência de outro. A anulação do ato administrativo por ilegalidade não circunscreve a jurisdição administrativa, mas se verifica na instância administrativa, seja por iniciativa da própria autoridade, seja em virtude de recurso hierárquico ou mediante o poder de vigilância exercido por outra autoridade superior. A anulação ex officio enquadra-se na competência normal da administração pública e corresponde à declaração espontânea ou provocada da nulidade, independentemente de pronunciamento judicial.

O desvio de poder não é um princípio estranho ao Direito Norte-americano. Embora não se apresente como no ordenamento jurídico Francês e Italiano, assemelha-se por conceito processual específico e por ser submetido a uma jurisdição administrativa.

A aproximação entre o sentido do "abuse of discretion" e o conteúdo do "excés de pouvoir" refere-se, como condição de validade da discrição administrativa, à subordinação ao fim legal (subordination of scope), em que a finalidade deve se referir ao interesse público cogitado em lei. Portanto, o direito americano adota, a propósito da jurisprudência italiana e francesa, a vinculação do ato administrativo, com respeito ao fim legal e à tipicidade do escopo, que não se altera. 
No Direito Brasileiro, o vício do desvio de poder apresenta-se quando o agente administrativo, servindo-se de uma competência, que em abstrato possui, busca uma finalidade alheia a qualquer interesse público.

Nesse caso, atua para alcançar fim pessoal: perseguição a alguém ou favoritismo do próprio agente. Em outra modalidade, manejando uma competência que, em abstrato possui, busca atender finalidade pública que não é aquela própria, específica, da competência utilizada. Nessa hipótese, o administrador pode não ter agido de má fé, mas ter se servido de competência imprópria ou equivocadamente suposto que a competência utilizada fosse prestante, de direito, para alcançar a finalidade visada.

No entanto, haverá, do mesmo modo, incorrido em desvio de poder. Nesse sentido, ajusta o Direito Português com o Direito Brasileiro.

No Direito Francês, segundo RIVERO (1978:223 e ss), como no Direito Brasileiro, o

caso mais evidente de desvio de poder é a perseguição pelo autor do ato de um fim estranho ao interesse gerado: satisfação de uma inimizade pessoal, paixão política ou ideológica (...) ou ainda, há desvio de poder quando o fim perseguido, se bem que de interesse geral, não é o fim preciso que a lei assinava a tal ato (...).

Conforme descreve WALINE (1963:451), é caso de nulidade do ato administrativo quando "em numerosos casos de intenção do legislador, conferindo certos poderes à administração, é a de que esta os utilize, não em vista de qualquer interesse público, mas exclusivamente em vista de um fim bem determinado, neste caso, todo uso de um tal poder em vista de um fim, mesmo que de utilidade pública, diverso daquele que foi previsto e querido pelo legislador, é um desvio de poder".

Nesse sentido, ocorre o desvio de poder, que vicia e gera a nulidade do ato.

\section{A prova do desvio de poder no direito comparado}

Em regra, quem age mal intencionadamente, procura acautelar-se contra os riscos de exibir ou entremostrar sua incorreção. Daí, procura disfarçar o vício, cercando-se de pretensas justificativas para o ato, a fim de encobrir-lhe a mácula.

No Direito Francês, assertoa RIVERO (1962:224) que tal qual no Direito Brasileiro, "a dificuldade se situa no terreno da prova. A intenção é um elemento psicológico, difícil de ser determinada, salvo quando o autor se explica abertamente o que será tanto mais raro quanto mais inconfessável por ela". Já WALINE (1963:481) sublinha com maior rigor esta dificuldade pois, quando "(...) uma autoridade administrativa comete um desvio de poder, ela está de má fé, e sabe que traiu a intenção do legislador, assim, não tem a ingenuidade de indicar as razões inconfessáveis que inspiraram o seu ato; dissimula seus verdadeiros móveis que o juiz 
deve procurar; em vista de todas as circunstâncias em que o ato foi praticado". Essa é uma prova difícil de se fazer.

RIVERO (1962) esclarece ainda que o "Conselho de Estado — órgão jurisdicional Francês para lides administrativas exigia que o desvio de poder resultasse do ato em si mesmo, vindo depois a evoluir, admitindo-se que a prova provenha de outros elementos, tais como: 'outras peças escritas, circunstanciais nas quais se produziu o ato, inexatidão dos motivos alegados que deixam transparecer o motivo verdadeiro e etc'. E conclui que o Conselho de Estado: Procura menos uma prova manifesta que uma convicção a qual pode resultar de um feixe de indícios convergentes".

Como noticia GARCIA DE ENTERRIA (1953:443-4):

Facilmente se compreende que esta prova não pode ser plena, já que não é presumivel que o ato viciado confesse expressamente que o fim que o anima é outro, distinto do assinalado pela norma. Consciente desta dificuldade, assim como a de que a exigência de um excessivo rigor probatório privaria totalmente de virtualidade a técnica do desvio de poder, a melhor jurisprudência costuma afirmar que para que se possa declarar a extensão deste desvio" é suficiente a conviç̧ão moral que se forme o Tribunal "(Decisão de $I^{\circ}$ de dezembro de 1959) à vista dos fatos concretos que em cada caso resultem provados, conquanto não bastem meras presunções nem suspicazes e especiosas interpretações do ato da autoridade e da falta de intenção que o determina (Decisão de 7 de outubro de 1963).

Assim, o Direito Espanhol tomou a mesma medida do Direito Francês.

Sustenta GORDILLO (1975:33), nos Direitos Argentino, Francês e Espanhol, que o necessário é encontrar as "provas indiciárias ou elementos circunstanciais, uma vez que raramente no próprio ato, como em sua motivação, é que apareceria o vício. Donde, a prova, de regra, terá de resultar de um conjunto de circunstâncias exteriores do ato". Observa GORDILLO que o autor do desvio de poder "deixa rastros de sua conduta, que são demonstráveis por prova documental, testemunhal ou indiciária".

No Direito Brasileiro, assertoa BANDEIRA DE MELLO (1996:81) "que a investigação jurisdicional do desvio de poder emanada agrava a discricionariedade do agente administrativo. Não afeta o mérito do ato". Corresponde a um estrito exame de legalidade, como acentuou GARCIA DE ENTERRIA (1983:443): "El vicio de desviación de poder es um vicio de estricta legalidad".

Para detectar o desvio de poder, estranho a qualquer interesse público, cumpre analisar todo o conjunto de circunstâncias que envolva o ato. A determinação do fim legal e a prova de sua unificação são o que fundamentam o Poder Judiciário para efeitos de anulação do ato administrativo acoimado de desvio. Mesmo com indício ou prova de intenção dolosa ou de erro, o que caracteriza o desvio de poder é o abandono do fim legal, ou seja haver o agente exercido sua competência para a prossecução de fim que não lhe é próprio. 


\section{Conclusões}

A construção da teoria do fenômeno jurídico, a que se denomina desvio de poder, surgiu, precisamente, com o objetivo de impor limitação ao âmbito da atuação discricionária por parte da Administração Pública, com vistas à exclusão de qualquer incidência no campo da arbitrariedade.

A teoria do desvio de poder teve o mérito de focalizar a noção do interesse público como centro da legalidade do ato administrativo. Caracteriza-se o desvio de poder quando o agente se afasta do alvo obrigatório, em virtude do qual a lei o habilitou a operar.

A anulação dos atos administrativos, por desvio de poder, teve seu marco inicial na jurisprudência do Conselho de Estado da França, por ocasião do caso Lesbats, em 25 de fevereiro de 1864 .

No Direito Francês, diferentemente do Direito Brasileiro, o desvio de poder é vício que afeta o ato, mediante o qual a Administração prossegue rumo diverso do que the foi assinalado pela norma jurídica.

Semelhante ao Direito Francês, o Direito Italiano diverge do Direito Brasileiro, uma vez que o legislador italiano não definiu o conceito de excesso de poder como causa anulatória do procedimento administrativo.

A jurisprudência italiana acompanha a lição do Conselho de Estado da França e repele $o$ ato administrativo inspirado $\mathrm{em}$ fim de natureza privada que objetive fim público diverso do endereço legal.

No Direito Português, tanto a doutrina quanto a jurisprudência adotam a nulidade pelo desvio de poder, mesmo quando a autoridade, embora deixando de executar o fim legal, procure atingir outro objetivo de interesse público; diferentemente do Direito Italiano e Francês, para os quais o fim legal do ato administrativo constitui vinculação da Competência. Nesse sentido, o direito norte-americano adota a posição de que a vinculação do ato administrativo ao fim legal obriga a tipicidade do escopo.

Os Direitos Argentino e Uruguaio, como o Direito Brasileiro, condicionam a validade dos atos administrativos à finalidade legal.

A teoria do Desvio de Poder, no Direito Brasileiro, como causa de nulidade de atos administrativos, foi elaborada por Seabra Fagundes e por Victor Nunes Leal. A mais expressiva decisão judiciária brotou do acórdão, de 28 de julho de 1948, do Tribunal de Justiça do Rio Grande do Norte, na apelação civil n ${ }^{\circ} 1.422$ com fundamento no voto do desembargador SEABRA FAGUNDES. Nesse sentido, o Direito Brasileiro é semelhante ao Direito Francês (caso Lesbats).

Nos Direitos estudados, o caso mais evidente de desvio de poder é a perseguição pelo autor do ato de um fim estranho ao interesse gerado.

Ajustam-se no mesmo compasso o Direito Português com o Direito Brasileiro quando o agente administrativo, servindo-se de competência que em abstrato possui, busca finalidade alheia a qualquer interesse público.

Além disso, para detectar o desvio de poder, estranho a qualquer interesse público, cumpre analisar todo o conjunto de circunstâncias que envolve o ato, verificando-se, assim, se a discricionariedade alegável foi bem usada ou se corresponde apenas a um pretexto para violar o fim legal e saciar objetivos pessoais. 
O necessário é encontrar "provas indiciárias ou circunstanciais", uma vez que raramente no próprio ato e em sua motivação apareceria o vício. O desvio de poder admite a prova indireta, que resulta do conjunto de circunstâncias exteriores do ato.

\section{Referências bibliográficas}

BANDEIRA DE MELLO, Celso Antônio. Discricionariedade e Controle Jurisdicional. 2 ed. São Paulo: Malheiros. 1996.

BANDEIRA DE MELLO, Oswaldo Aranha. Princípios Gerais de Direito Administrativo. Rio de Janeiro: Ed. Forense. v. I. 1969.

BIELSA, Rafael. Derecho Administrativo. 4 ed. Buenos Aires: El Ateneo. v. I. 1947.

CAETANO, Marcelo. Manual de Direito Administrativo. 10 ed. Lisboa: 1973.

FAGUNDES, Miguel Seabra. O controle dos Atos Administrativos pelo Poder Judiciário. 3. ed, Rio de Janeiro: Forense. 1975.

FIORINI, Bartolomé A.. La Discrecionalidad en la Administration Publica. Editorial Alfa. BS. Aires: 1948.

FLEINER, Fritz. Principes Généraux de Droit Administratif Allemand. Paris: Delagrave. 1993.

GARCIA DE ENTERRÍA, Eduardo. Curso de Derecho Administrativo. 4 ed. Civitas: 1983. t.I.

GORDILlO, Augustin. Tratado de Derecho Administrativo. Buenos Aires: Macchi. t. I. 1975. cap. 8. Parte Geral. Id. ibid. cap. 9.

LAUBADÉRE, André de. Traité Élémentaire de Droit Administratif. LGDF. 5 ed. v. I. $1970 . n^{\circ} 894$.

LASO, Enrique Sayagnés. Tratado de Derecho Administrativo. 4 ed. Montevidéu: v. I. 1974.

LEAL, Vitor Nunes. Poder Discricionário e ação arbitrária da Administração. In. Revista de Direito Administrativo. v. 14. 1948.

LIMA, Ruy Cirne. Princípios Gerais de Direito Administrativo. Porto Alegre: Sulina. 1954.

PINTO, Roger. La crise de lEtat aux Etats Unis. Paris: 1951.

TÀCITO, Caio. Direito Administrativo. 5 ed. Saraiva. Rio de Janeiro: 1975. Desvio do Poder. p. 93-107. In. Reportório Enciclopédico do Direito Brasileiro. J.M. de Carvalho Santos, coadjuvado por José de Aguiar Dias. v. XVI. Rio de Janeiro: Editor Borsoi.

RIVERO, Jean. Droit Administratif. 7 ed. Précis Dalloz. Paris: 1975. nº 250 e 261. RODÓ, Lopez. Le pouvoir discrétionnaire de lAdministration. Revue du Droit Public et de la Science Politique. 1953. $\mathrm{n}^{\circ} 3$.

SCHWARTZ, Bernard. American Administrative law. Londres: 1950.

WALINE, Marcel. Traité Élémentaire de Droit Administratif. 5. ed. Recueil Sirey. Paris: 1950.

Droit Administratif. 9 ed. Sirey: 1963.

ZANOBINI, Guido. Corso di Diritto Admministrativo. 5. ed. Da Dott. A. Giuffrè. v. II. 1947. 